\title{
Comment on Tae-Hee Kim et al.: Genetic alteration in ovarian cancer
}

\author{
Ivo Meinhold-Heerlein · S. Hauptmann
}

Published online: 30 July 2014

(c) Springer-Verlag Berlin Heidelberg 2014

We thank for the additional information [1] about the genetic changes in ovarian cancer. In future it will be important to investigate all possible genetic, translational, post-translational and also epigenetic changes in the different ovarian cancer subtypes. Research will also give additional insights in ovarian cancer pathogenesis. This will be the basis for the development of novel methods to diagnose and treat ovarian cancer early and efficiently to improve the prognosis of this fatal disease.
Conflict of interest None.

\section{Reference}

1. Kim T-H, Lee H-H, Hwang J-Y, Kim J-H, Jang W-C, Lee A (2014) Genetic alteration in ovarian cancer. doi:10.1007/s00404014-3392-4

I. Meinhold-Heerlein $(\square) \cdot$ S. Hauptmann

Department of Gynecology and Obstetrics, University Hospital

Aachen, Pauwelsstraße 30, 52074 Aachen, Germany

e-mail: imeinhold@ukaachen.de

I. Meinhold-Heerlein · S. Hauptmann

Institute of Pathology, Hospital Düren, Düren, Germany 